\title{
Estudos da paz: origens, desenvolvimentos e desafios críticos atuais
}

\author{
Peace studies: origins, developments \\ and current critical challenges
}

DOI: $10.21530 /$ ci.v12n1.2017.611

Gilberto Carvalho de Oliveira ${ }^{1}$

\section{Resumo}

Embora os estudos da paz coloquem no núcleo da sua agenda de pesquisa alguns dos desafios mais graves e urgentes do nosso tempo - incluindo todas as formas de violência, as causas dos conflitos e as condições para a paz -, é curioso notar a marginalidade, ou quase invisibilidade, dessa disciplina no meio acadêmico brasileiro, bem como a escassez de bibliografia produzida no Brasil dedicada às bases conceituais e metodológicas próprias dessa área de estudos. A fim de contribuir para uma maior visibilidade dos estudos da paz, este artigo tem por objetivo traçar um panorama geral do percurso de consolidação dos estudos da paz como disciplina acadêmica, desde o seu nascimento na década de 1950 até a atualidade. Dentro desse propósito, o artigo procura destacar as origens e os elementos definidores centrais dos estudos da paz, os desenvolvimentos conceituais sobre a violência e a paz ocorridos na obra de Johan Galtung, considerado uma das referências centrais dessa área de estudos, e os principais desdobramentos e desafios dos estudos da paz na atualidade.

Palavras-chave: Conflito, Galtung, Pesquisa da paz, Resolução de conflito, Violência.

\begin{abstract}
Although peace studies put at the core of its research agenda some of the most serious and urgent challenges of our time - including all forms of violence, the causes of conflict and the conditions for peace -, it is curious to note the marginality, or almost invisibility, of this discipline in the Brazilian academia, as well as the scarcity of the literature dedicated to the conceptual and methodological basis of this area of study produced in Brazil. In order to contribute to greater visibility of peace studies, this article aims to outline an overview of the consolidation of the discipline, from its origins in the 1950s to the present. For this
\end{abstract}

1 Professor-Adjunto da Universidade Federal do Rio de Janeiro (UFRJ). Email: gilbertooliv@gmail.com Artigo submetido em 12/01/2017 e aprovado em 19/04/2017. 
purpose, the paper highlights the main defining elements of peace studies, the conceptual developments about violence and peace in Johan Galtung's work, considered one of the central references of the discipline, as well as the main developments and challenges of peace studies today.

Keywords: Conflict, Galtung, Peace research, Conflict Resolution, Violence.

\section{Introdução}

Os estudos da paz constituem a área de pesquisa acadêmica que incorpora o compromisso mais claro e explícito com a não-violência e a organização pacífica das relações sociais nos níveis local, nacional, regional e internacional. Desde o seu surgimento como área disciplinar organizada, institucionalizada em universidades e centros de pesquisa nos Estados Unidos e na Europa há cerca de sessenta anos atrás, os estudos da paz têm procurado demonstrar que a paz não é apenas um ideal utópico, ou um estado contingente eventualmente alcançado entre guerras inevitáveis, mas é um objeto de pesquisa acadêmica a ser estudado em seus próprios méritos e a ser colocado em prática através de políticas concretas. Nesse sentido, os estudos da paz têm acumulado um vasto manancial de conhecimentos - conceitos, teorias, métodos e análises empíricas - que, em seu conjunto, fornecem indicações relevantes para a compreensão das causas dos conflitos violentos e das condições para a paz.

Há uma quantidade incontável de tópicos que alimentam a agenda dos estudos da paz, incluindo aspectos tão diversos quanto as causas da guerra; o problema das armas nucleares, do desarmamento e do controle de armas; as técnicas de resolução de conflitos; as operações de paz; a desmobilização, reconciliação e reconstrução pós-bélica; as migrações e os deslocamentos internos; a resistência não-violenta; as variadas formas de violência estrutural e cultural; a educação para a paz; as condições para uma paz positiva (redução das desigualdades econômicas, promoção da justiça social, redução da exploração e da opressão). O que esses poucos tópicos demonstram - e a lista poderia ser expandida para muito além desse horizonte - é que a agenda dos estudos da paz lida com algumas das questões mais urgentes e graves do nosso tempo, o que faz com que a relevância dessa área de pesquisa seja inquestionável.

Contudo, ainda que os estudos da paz se tenham institucionalizado em centenas de universidades e centros de pesquisa em todo o mundo (WIBERG, 2005), levando 
a um crescente número de estudantes solidamente treinados nessa área, tanto em nível de graduação quanto de pós-graduação, ainda é notável a marginalidade da disciplina no meio acadêmico brasileiro e a escassez de bibliografia produzida no Brasil dedicada às bases conceituais e questões metodológicas específicas dessa área de estudos. Esse aspecto parece surpreendente quando se considera o tradicional posicionamento externo do país em favor da resolução pacífica de conflitos, o seu crescente envolvimento nas operações de paz e as formas crônicas de violência direta, estrutural e cultural que hoje impactam as relações sociais nas zonas rurais e em grande parte das cidades brasileiras, colocando sérios desafios à construção de um ambiente de paz abrangente e sustentável no país. Embora esses aspectos remetam a questões típicas da agenda dos estudos da paz, dentro de seus variáveis níveis de análise, é notória a falta de ênfase e de institucionalização dessa disciplina nos currículos universitários brasileiros. Ainda que se deva notar um movimento embrionário de afirmação dessa área de pesquisa - traduzido sobretudo pelos esforços de criar uma Rede de Pesquisa em Paz, Conflitos e Estudos Críticos de Segurança (PCECS) e pela recente realização do I Encontro Brasileiro de Estudos para a Paz ${ }^{2}$ - não se pode deixar de ressaltar que muito esforço ainda precisa ser feito no sentido de tirar os estudos da paz da invisibilidade no contexto brasileiro.

O propósito deste artigo é traçar um panorama geral do percurso de consolidação dos estudos da paz como disciplina acadêmica, desde o seu nascimento na década de 1950 até a atualidade. Dentro desse propósito, o artigo procura destacar as origens e os elementos definidores centrais dos estudos da paz (primeira seção), os desenvolvimentos conceituais sobre a violência e a paz ocorridos na obra de Johan Galtung, considerado uma das referências centrais dessa área de estudos (segunda seção) e os principais desdobramentos e desafios dos estudos da paz na atualidade (terceira seção). Trata-se, portanto, de um texto introdutório que não propõe acrescentar conhecimentos originais e nem avançar o debate teórico além do já existente na disciplina, mas sim traçar um mapa geral dos seus contornos principais. Deve-se acrescentar, ainda, que a limitação imposta pela dimensão do artigo impõe uma abordagem seletiva, dentro da qual os desenvolvimentos conceituais da obra de Galtung são privilegiados, o que obviamente não esgota o amplo leque de temas, autores e pontos de vista que caracterizam a diversidade própria da área disciplinar aqui tratada. Mesmo dentro desses limites, considera-se

2 Ver: < http://pcecs.blogspot.com.br/ > . 
que o artigo oferece uma contribuição relevante não só para professores, estudantes e pesquisadores brasileiros ${ }^{3}$ interessados num panorama geral e introdutório sobre esta área de estudos, mas também para leitores que, mesmo sem vinculação acadêmica, atuam nas esferas governamental e não-governamental exercendo atividades relacionadas a ações humanitárias e intervenções em zonas de conflito e de violência endêmica.

\section{Elementos definidores centrais dos estudos da paz}

Embora o pensamento sobre a paz remonte à antiguidade, estando presente em diversas tradições religiosas, correntes filosóficas e vertentes do movimento pacifista, os estudos da paz - enquanto área disciplinar organizada, institucionalizada em universidades e centros de pesquisa, dotada de um corpo teórico próprio e de publicações e fóruns de discussão especializados - constituem um empreendimento relativamente novo. Com essas características institucionais, o nascimento dos estudos da paz ocorreu no final da década de 1950, nos Estados Unidos, embora sem se referir explicitamente ao termo "paz" no seu nome de batismo. O que se viu nesses momentos iniciais foi a emergência da expressão "pesquisa do conflito" (conflict research), empregada para designar a preocupação com a resolução pacífica dos conflitos em larga escala, fornecendo as balizas intelectuais que levaram acadêmicos como Kenneth Boulding, Herbert Kelman e Anatol Rapoport a criarem o Journal of Conflict Resolution em 1957 e o Center for Research on Conflict Resolution na Universidade de Michigan em 1959. Essa nascente agenda de pesquisa procurou buscar na revolução behaviorista - isto é, no movimento que projetava sobre as ciências sociais um aparato de validação científica inspirado nas ciências da natureza - o mesmo conjunto de ferramentas metodológicas que os realistas e estrategistas começavam a abraçar para se legitimarem como produtores de conhecimento científico (JCR, 1957).

Paralelamente a esses esforços, surgiu na Europa uma comunidade de pesquisadores com objetivos semelhantes. Porém, ao contrário da timidez com que a palavra "paz” aparecia na proposta dos colegas norte-americanos, os

3 Como professor de estudos da paz num curso de graduação, tenho constatado a demanda dos alunos por referências bibliográficas dessa área, escritas em português, que auxiliem os seus estudos. Considerando a possibilidade de que os estudos da paz se tornem mais visíveis e presentes nos currículos acadêmicos, em função dos recentes movimentos de institucionalização da disciplina no Brasil, é possível que essa demanda venha a aumentar, o que reforça a relevância aqui apresentada. 
pesquisadores europeus optaram por dar uma centralidade a esse termo, colocando o conceito de paz no núcleo do seu projeto intelectual e explicitando a palavra paz no título da sua atividade de pesquisa (peace research) e no nome dos seus institutos e departamentos acadêmicos. "Nós não temos medo da palavra 'paz'”, 4 afirmava Galtung no editorial de lançamento do Journal of Peace Research (JPR, 1964, p. 4), vinculado ao International Peace Research Institute Oslo (PRIO), criado em 1959 pelo mesmo acadêmico. Nesse editorial, Galtung propunha uma perspectiva metodológica mais flexível, ainda que se mantivesse firme no propósito de fazer da paz um objeto de estudo científico. Desse modo, mesmo defendendo um estatuto científico e a formulação de hipóteses e proposições gerais sobre a paz, o editorial inaugural do Journal of Peace Research sugeria que a consistência teórica, e não a confirmação empírica, deveria ser a preocupação central da pesquisa da paz (JPR, 1964, p. 4). Também relevante era o fato do editorial defender explicitamente que a apreciação ideológica poderia coexistir com a avaliação empírica, indicando uma posição menos rígida em relação à distinção entre fato e valor.

Nas origens desse projeto encontrava-se, portanto, a pretensão de desenvolver uma "ciência normativa" da paz, dentro da qual o rigor analítico e o respeito aos protocolos científicos de validação do conhecimento seriam temperados pela ideia de que a violência e a guerra têm um valor negativo - devendo, desse modo, ser rejeitadas ou, pelo menos, reduzidas - e que a produção teórica deveria contribuir, na prática, para a prevenção, a mitigação e a resolução dos conflitos violentos. Influenciada principalmente pela extraordinária capacidade de Galtung de diversificar suas abordagens conceituais e metodológicas, a designação dessa área de pesquisa evolui gradualmente para a expressão "estudos da paz", que passou a ser vista como um grande rótulo "guarda-chuva" destinado a abrigar não só o tipo de pesquisa neopositivista, fiel às origens behavioristas da pesquisa do conflito e da pesquisa da paz, mas também as abordagens mais reflexivas e críticas que foram incorporadas à disciplina com os conceitos de violência estrutural e cultural e com as influências construtivistas, críticas, pós-estruturalistas, feministas e pós-colonialistas introduzidas na disciplina a partir das décadas de 1980 e 1990. Dentro desse quadro passaram a conviver não só as agendas de pesquisa racionalistas, que até hoje guiam a orientação editorial de revistas tradicionais da área como o Journal of Conflict Resolution e o Journal of Peace Research, mas

4 Tradução livre do autor: "we are not afraid of the word 'peace'”. 
também as agendas mais críticas e reflexivistas que se fazem representar através de publicações acadêmicas surgidas posteriormente, tais como a Peace and Change e a Peace and Conflict Studies.

Dentro desse panorama, é importante notar que os estudos da paz assumiram, desde os seus momentos iniciais, uma identidade intelectual que se afirmava em oposição à corrente realista das Relações Internacionais e aos estudos estratégicos. Se a reflexão científica sobre a guerra e a paz após o fim da II Guerra Mundial constituía um monopólio da tradição realista e estratégica - onde a máxima si vis pacem, para bellum ${ }^{5}$ era auto reproduzida e auto reforçada como verdade fixa e universal -, a emergência da pesquisa do conflito e da pesquisa da paz nos anos 1950/1960 representou um desafio a essa concepção dominante. Ao assumirem que a paz não era um mero estado contingente alcançado por vitórias militares entre guerras inevitáveis, mas se definia por seus próprios méritos como um processo que podia ser construído através de políticas e intervenções orientadas primordialmente para afirmar a vida das pessoas e produzir um mundo melhor, mais igualitário e justo, livre das manifestações diretas e indiretas de violência, os estudos da paz propuseram uma ruptura com o pensamento tradicional, rejeitando a máxima "se queres a paz, prepara-te para a guerra” e colocando em seu lugar uma outra noção igualmente radical: se queres a paz, prepara-te para a paz (DUNN, 2005, p. 1). Portanto, a ambição de converter a paz em objeto de pesquisa acadêmica, sem que isto implicasse em negar o compromisso ético com a não-violência e com o propósito político da sua produção de conhecimento, sempre esteve presente no projeto intelectual dos estudos da paz e continua a ser um dos seus elementos definidores centrais.

Um segundo aspecto característico dos estudos da paz é a sua auto definição como área interdisciplinar de pesquisa. As duas grandes revistas científicas da área deixam claro, desde as suas fundações, esse elemento definidor. Conforme observam os editores do número inaugural do Journal of Conflict Resolution, os assuntos internacionais têm sido um domínio quase que exclusivo dos "historiadores e cientistas políticos", bem como de profissionais "como diplomatas e militares"; porém, continuam os editores, a prevenção da guerra requer que se vá além, trazendo para esse domínio os conhecimentos produzidos pelos sociólogos, psicólogos, educadores e pioneiros da ciência behaviorista (JCR, 1957). O editorial do primeiro número do Journal of Peace Research enfatiza,

5 "Se queres a paz, prepara-te para a guerra". 
igualmente, que a pesquisa da paz deve ser interdisciplinar (JPR, 1964, p. 4). Sobre essa característica, Galtung $(1985,2010)$ tem sido incansável em chamar a atenção para o fato de a paz ser um tópico demasiadamente complexo para ter a sua compreensão limitada a um quadro unidimensional de análise, geralmente orientado por disciplinas tradicionais como a história ou o direito internacional. Por essa razão, o autor considera que o conceito de paz deve ser permanentemente problematizado e que a pesquisa das condições para a paz deve "ligar o abismo existente entre o ‘tradicional' e o ‘moderno’ nas ciências sociais”6 (1985, p. 143), criando uma rede de pesquisadores de várias disciplinas (psicologia, sociologia, politologia, etc.), dentro da qual os pesquisadores da paz possam ser integrados. $\mathrm{O}$ autor vai mais longe ainda ao defender que, estimulados pelo diálogo e o intercâmbio intelectual dentro dessa rede interdisciplinar, os pesquisadores da paz caminhem para a transdisciplinaridade, ou seja, para uma crescente síntese e integração das perspectivas e abordagens dessas diversas disciplinas dentro das suas mentes individuais $(1985 ; 2010)$.

Um terceiro aspecto marcante dos estudos da paz é a sua característica multinível. Isto significa que os estudos da paz assumem o compromisso de olhar para os diversos níveis implicados na formação dos conflitos e nas condições para a paz, incluindo o individual, o comunitário, o estatal e o internacional. De fato, a tradicional centralidade do Estado e as convencionais fronteiras entre as esferas interna e interna que marcam as Relações Internacionais têm sido desafiadas pelos estudos da paz desde os seus momentos iniciais, devido ao caráter unidimensional e redutor que essas categorias impõem ao estudo dos conflitos e da paz. Ainda que os conflitos internacionais permaneçam entre os focos de preocupação relevantes dos estudos da paz, isto não implica em assumir que as únicas linhas que "cruzam a humanidade", criando obstáculos à integração e acentuando "a disposição para usar a violência”, sejam as fronteiras entre Estados; portanto, usar o Estado como único critério para definir o nível de análise nos estudos da paz parece redutor, uma vez que existem outras fronteiras igualmente importantes na formação e divisão de grupos (tais como linhas étnicas, religiosas, sociais ou econômicas), potencialmente capazes de produzir antagonismos que levam à violência (JPR, 1964).

Finalmente, o elemento que talvez defina os estudos da paz de uma forma mais particular seja a conjugação de uma epistemologia negativa e uma de epistemologia

6 Tradução livre do autor: "to bridge the gap between 'traditional' and 'modern' social sciences”. 
positiva na problematização do conceito de paz (RASMUSSEN, 2003). Desde o início de sua obra, Galtung traz no núcleo do seu projeto intelectual a noção de que os estudos da paz se desdobram em dois ramos de pesquisa, baseados em duas perspectivas epistemológicas distintas: uma negativa e outra positiva (JPR, 1964). Da primeira perspectiva, a paz é definida de uma forma estreita a partir do que ela não é ou do que ela nega: a violência física e a guerra. Essa noção, batizada por Galtung de "paz negativa”, traduz uma concepção minimalista de paz, restrita à ausência das manifestações diretas e aparentes da violência, que corresponde não só à perspectiva compartilhada pelo realismo nas Relações Internacionais e pelos estudos estratégicos, mas também às perspectivas do senso comum e dos movimentos pacifistas, que geralmente enxergam a paz através das lentes do ativismo antiguerra. Cabe à pesquisa da paz, dentro dessa epistemologia negativa, preocupar-se com as manifestações explícitas da violência, o que leva os pesquisadores a se dedicarem à compreensão das razões, causas, dinâmicas e formas de lidar com os efeitos diretos do conflito e da guerra. Dentro dessa moldura negativa da paz, os pesquisadores envolvem-se, por exemplo, com temas como diplomacia, negociação, mediação e outros instrumentos de gestão e resolução de conflitos; papel das organizações internacionais e do direito internacional na contenção da guerra; desarmamento e controle de armas, especialmente de armas nucleares, químicas e bacteriológicas; papel das organizações não-governamentais e dos mecanismos não-oficiais na resolução de conflitos; e outras formas de contenção ou supressão da violência física e aparente.

Da segunda perspectiva - e aqui está a grande novidade introduzida por Galtung - a paz define-se de uma forma maximalista a partir de tudo o que ela pode agregar: a mudança de mentalidades, o contato e o intercâmbio entre os grupos sociais, a educação, a pesquisa, a comunicação e o diálogo, as transformações sociais e econômicas, a cooperação institucional entre grupos e nações, e quaisquer outras propostas que se comprometam com “a integração humana” (JPR, 1964). Desse ângulo, a paz não se define pela mera ausência da violência física e direta - ainda que esta continue a ser uma das suas dimensões necessárias -, mas se expande para além desse horizonte, a fim de abranger qualquer iniciativa afirmativa que promova a integração humana. Essa segunda dimensão, que Galtung chama de "paz positiva", assume uma feição mais complexa e radical, indicando o compromisso com a construção de um sistema social global integrado, onde as mudanças sociais possam ser alcançadas através de meios não violentos. Dessa perspectiva positiva da paz, os pesquisadores envolvem-se, por exemplo, com 
temas relacionados aos direitos humanos; questões de gênero; desigualdades sociais e econômicas, desenvolvimento, redução da pobreza e combate à fome; bem-estar social; participação política; justiça social; transformações sociais não violentas; educação para a paz; reconstrução pós-conflito, reconciliação e justiça de transição; questões ambientais; pluralismo e diversidade cultural; diálogo e compreensão em todos os níveis, do interpessoal, ao intersocial, ao internacional. Dentro dessa dimensão positiva da paz, são cruciais os desenvolvimentos ocorridos na obra de Galtung, principalmente a partir do final da década de 1960, com o conceito de violência estrutural, e na passagem das décadas de 1980 pata 1990, com o conceito de violência cultural.

\section{Violência estrutural e os conceitos de peacekeeping, peacemaking e peacebuilding}

A introdução do conceito de violência estrutural na obra de Galtung e a sua articulação com o conceito de paz positiva ocorreu na passagem da década de 1960 para 1970, no contexto de um intenso debate interno fomentado pela crítica oriunda de jovens pesquisadores de orientação marxista, que acusavam a disciplina de se ter convertido num tipo de ciência aplicada, orientada para os interesses de "quem tem o poder de aplicá-la"7 (SCHMID, 1968, p. 229) e, como tal, uma fonte de conhecimento útil para o controle, a manipulação e a integração do sistema internacional pelos grupos dominantes. Da perspectiva desses jovens pesquisadores, os estudos da paz não passavam de numa espécie de pesquisa para a pacificação, produzindo um conhecimento orientado para a harmonização e o alívio imediato dos efeitos da violência, sem atentar para a necessidade de reestruturar radicalmente o sistema que estava na base dos antagonismos (DENCIK, 1970; STOHL; CHAMBERLAIN, 1972).

O conceito de violência estrutural proposto por Galtung (1969) responde, em grande medida, as críticas acima mencionadas. Definida como uma forma indireta de violência, cujas raízes estão na distribuição desigual de poder e de recursos nas sociedades ou entre as sociedades, a violência estrutural chama a atenção para um tipo de violência quase sempre latente, invisível ou disfarçada, que resulta das desigualdades sociais, das injustiças, da pobreza, da exploração e

7 Tradução livre do autor: "who has the power to apply it". 
da opressão. Desse modo, se o conceito de paz negativa se define pela ausência de violência direta, o conceito de paz positiva passa a ser definido como a ausência de violência estrutural e a ser articulado por Galtung através da noção de justiça social. A partir desse refinamento conceitual, a paz positiva - que na formulação original do autor ainda guardava uma dose de idealismo ao ser concebida genericamente como qualquer iniciativa voltada para a "integração humana” (JPR, 1964) - passa a ser concebida como a superação de todas as formas de desigualdades e injustiças sociais, dando à agenda de estudos da paz uma orientação mais reflexiva e emancipatória.

Essa dimensão estrutural da violência, reforçada por Galtung (1971) em sua teoria estrutural do imperialismo, traz para a teoria da paz as dinâmicas mundiais de exploração entre centro e periferia, bem como as disparidades de desenvolvimento dentro e entre nações, respondendo dessa forma à acusação de seus críticos mais radicais de que os estudos da paz, até então obcecados pelas dinâmicas estratégicas da Guerra Fria, pactuavam em grande medida ou pelo menos não se preocupavam na dimensão necessária - com a estrutura dominante de poder e com a lógica de autorreprodução da violência implicada nessa ordem dominante. Essa reorientação na teoria da paz e a sua conexão com a teoria do conflito e a teoria do desenvolvimento fornecem elementos essenciais para alimentar as reflexões de Galtung, desenvolvidas em meados da década de 1970, sobre três formas possíveis de intervenção em nome da paz no contexto de conflitos violentos: peacekeeping, peacemaking e peacebuilding (GALTUNG, 1976).

Se hoje os termos peacekeeping, peacemaking e peacebuilding pertencem ao léxico usual das chamadas operações de paz da Organização das Nações Unidas (ONU), é importante salientar que esses conceitos não existem na Carta das Nações Unidas. Na verdade, até a discussão proposta por Galtung em meados dos anos 1970, apenas as práticas tradicionalmente associadas ao termo peacekeeping (manutenção da paz) tinham alguma notoriedade, desde que Dag Hammarskjöld, Secretário-Geral da ONU, e Lester Pearson, Secretário de Assuntos Externos do governo canadense, tinham definido os princípios básicos que guiariam a atuação da Força de Emergência das Nações Unidas (UNEF I), criada para intervir em 1956 na chamada Crise de Suez (ONU, 1956). Pode-se dizer, portanto, que o termo peacekeeping tornou-se conhecido mais pelas práticas de intervenção realizadas sob mandato da ONU durante a Guerra Fria, do que por algum debate teórico ou alguma definição doutrinária nos documentos de alto nível daquela Organização. A discussão proposta por Galtung representa, dentro desse quadro, uma tentativa 
pioneira de teorizar as operações de paz e de propor um léxico apropriado às diferentes abordagens à paz, que só serão incorporadas à doutrina de intervenções da ONU cerca de quinze anos depois.

Em seu texto, Galtung destaca que o propósito do peacekeeping é "manter a paz” entre as partes em conflito através da interposição de uma terceira parte entre elas; isto significa, segundo o autor, que essa abordagem tem duas características definidoras centrais: ela é "dissociativa” (pois pressupõe que os antagonistas sejam mantidos segregados geograficamente, sob a ameaça de punição caso transgridam os limites dessa separação), e reflete uma concepção negativa da paz (pois limita-se à manutenção da ausência de violência direta). A segunda categoria o peacemaking ("restabelecimento da paz") - confunde-se com a abordagem de resolução de conflitos e reflete os esforços diplomáticos de negociação de um acordo que tenha um efeito apaziguador e possa ser ratificado pelas partes em conflito. Esses esforços de negociação de um acordo podem surgir entre as próprias partes em conflito ou com a ajuda de uma terceira parte. Ainda que Galtung considere essa abordagem importante e necessária, suas limitações também são relevantes. Em primeiro lugar, o seu foco também se limita à interrupção da violência direta, refletindo, portanto, uma concepção negativa da paz. Em segundo lugar, e talvez mais importante, o peacemaking depende do empenho e do comprometimento das lideranças de cada parte; como tal, é uma abordagem elitista e sujeita a flutuações de opiniões e retrocessos em função da eventual mudança dos atores-chave durante as negociações ou no período posterior ao acordo negociado. Também problemáticos são os casos, bastante frequentes segundo Galtung, de acordos produzidos sob pressão de uma terceira-parte que não refletem, necessariamente, as posições das partes em conflito. Isso mostra que as ações de peacemaking podem não ser suficientes para sustentar um sistema de paz, o que leva à necessidade de uma terceira abordagem - o peacebuilding ("construção" ou "consolidação" da paz) - que olhe de uma forma mais profunda para as fontes da violência estrutural e procure superá-las através da construção de uma paz positiva.

Essa terceira abordagem, de caráter "associativo" (contrário ao perfil dissociativo do peacekeeping), tem por propósito agregar as partes dentro de uma estrutura de paz que substitua a estrutura de violência que está na base do conflito. Nesse sentido, o peacebuilding requer que a estrutura que produz a violência seja identificada e substituída por uma estrutura alternativa de paz, mais igualitária, justa e livre de dominação, repressão e exploração - o que leva, segundo Galtung, a uma preocupação mais radical com medidas de desenvolvimento social. Desse 
ponto de vista, afirma o autor, o peacebuilding vai além da abordagem dissociativa do peacekeeping e dos esforços diplomáticos ad hoc para resolver as manifestações superficiais do conflito que caracterizam o peacemaking. O peacebuilding envolve uma estrutura social mais horizontalizada, portanto menos hierarquizada, onde as disparidades de desenvolvimento entre os indivíduos, classes, grupos, nações e regiões sejam reduzidas. Desse modo, as condições para uma paz positiva podem ser alcançadas: "assim como um corpo saudável pode produzir os seus próprios anticorpos sem a necessidade da administração ad hoc de medicamentos”, destaca Galtung recorrendo às suas usuais metáforas médicas, um "corpo mundial saudável” é capaz de produzir seus próprios "anticorpos" contra a violência; para isto, "é preciso encontrar estruturas que removam as causas da guerra e ofereçam alternativas às guerras em situações onde elas possam surgir”" (1976, p. 297-298, itálico no original). Na base das reflexões de Galtung, portanto, está a noção de que só as transformações estruturais e a justiça social promovidas pelo peacebuilding são capazes de produzir os "anticorpos" contra a violência, o que sugere uma ideia de paz autossustentável que só será incorporada ao léxico internacional mais de uma década depois, após o fim da Guerra Fria, com a revitalização do papel da ONU na construção de uma ordem mundial mais pacífica.

\section{Desdobramentos e desafios dos estudos da paz no pós-Guerra Fria}

No início dos anos 1990, Galtung dá mais um salto na sua teoria da paz. O autor observa que alguns aspectos próprios da esfera simbólica da existência humana (religião, ideologia, arte, linguagem, ciência, etc.) podem reforçar as formas diretas e estruturais de violência, legitimando-as ou fazendo com que elas sejam percebidas como corretas - ou pelo menos pareçam não erradas - aos olhos da sociedade (GALTUNG, 1990). Essas manifestações simbólicas, que Galtung chama de violência cultural, atuam através de mecanismos sutis e indiretos, exercendo uma função importante na construção de identidades coletivas que podem contribuir para a estabilização de determinadas ordens sociais onde formas diretas e estruturais de violência são vistas como "normais" (1990). O racismo, o machismo, as superstições, os fundamentalismos religiosos, os nacionalismos, o militarismo, as ideologias, o colonialismo, a meritocracia, as etnias e outras

8 Tradução livre do autor: "structures must be found that remove causes of wars and offer alternatives to war in situations where wars might occur”. 
construções simbólicas geralmente fundadas em relações binárias do tipo bom/ mau, escolhido/não escolhido, superior/inferior, amigo/inimigo ou racional/ emocional ilustram esse tipo de violência cultural, servindo como mecanismo de justificação ou legitimação de outras formas de violência direta e estrutural.

Com essa nova categoria conceitual, Galtung completa o que ele batiza de "triângulo da violência” (1996), onde num dos vértices está a violência direta e nos outros dois estão as formas indiretas de violência: a estrutural e a cultural. Projetando esse triângulo sobre o conceito da paz, Galtung chega a uma equação complexa, onde a paz negativa se define pela eliminação da violência direta e a paz positiva pela eliminação das duas formas de violência indireta: a estrutural e a cultural. O ponto de chegada dessa longa trajetória é uma concepção abrangente de paz que corresponde ao somatório da paz negativa com a paz positiva, sendo a última o somatório da paz estrutural com a paz cultural (figura 1).

Figura 1: Triângulos da Violência e da Paz Direta, Estrutural e Cultural de Galtung
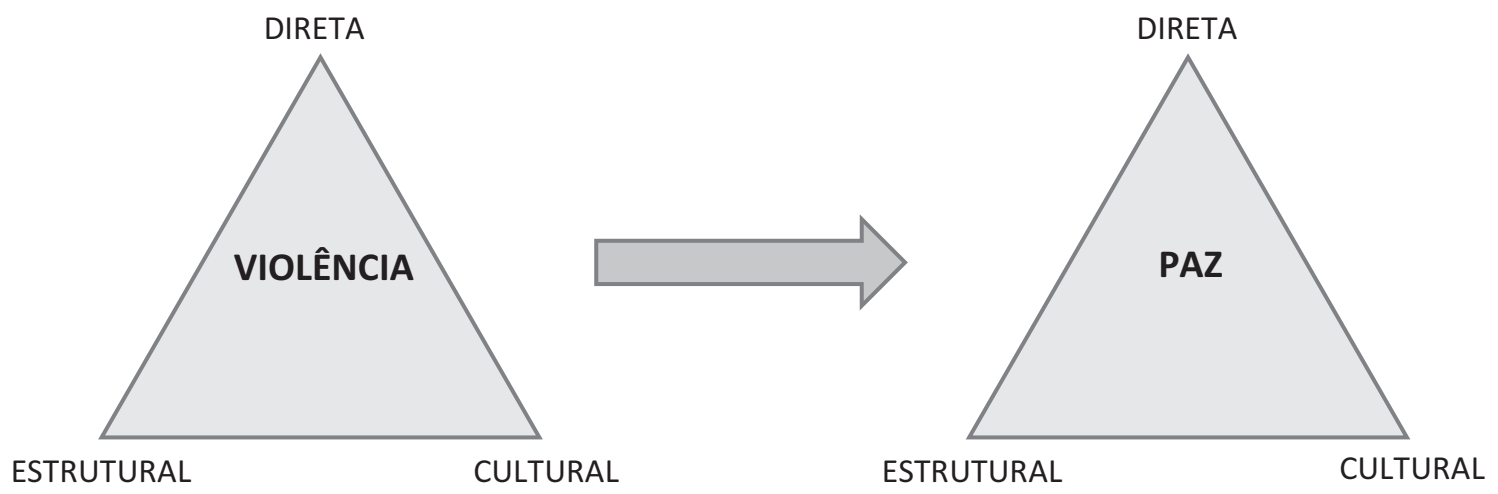

$P A Z=P n+P p$

Onde: Pn é a paz negativa (paz direta) e Pp é a paz positiva (paz estrutural + paz cultural)

Fonte: GALTUNG, 1996.

Esses últimos desenvolvimentos na obra de Galtung surgem num contexto fortemente influenciado pela ideia de uma ordem mundial alternativa e pelas questões de identidade que impactam o estudo da política internacional no fim da Guerra Fria. Dentro desse quadro, as preocupações com a paz e a segurança reorientam-se para questões inteiramente novas. Perante um número crescente de conflitos civis localizados na periferia do centro desenvolvido do sistema (Ex-Iugoslávia, Camboja, Somália, Ruanda, Serra Leoa, Libéria, República Democrática do Congo, Sudão, etc.), os estudos das causas da guerra e das condições para a paz emergem dentro de novos parâmetros. Ao olhar para esses conflitos, rotulados 
de "novas guerras" (KALDOR, 1999; KEEN, 1998; RENO, 1999; DUFFIELD, 2001) ou de conflitos "intratáveis" ou "persistentes" (AZAR, 1990, 2003), diversos autores observam características que não mais se ajustam às dinâmicas sistêmicas da competição bipolar e nem ao tipo de guerra convencional entre Estados marcado pelo enfrentamento de forças armadas profissionalizadas para atingir objetivos políticos claramente definidos. Nessa "nova" conflitualidade, onde se observam uma mistura complexa de atores governamentais e não-governamentais, agendas econômicas oficiais e paralelas, degradação ambiental e escassez de recursos naturais, bem como profundas divisões étnicas, culturais e religiosas, o ponto crucial destacado pelos autores é que os conflitos contemporâneos se prolongam indefinidamente, sem um ciclo claro de gênese, progressão, redução e terminação da violência, tornando-se pouco permeáveis aos esforços formais de resolução de conflitos e consolidação da paz (AZAR, 1990, 2003; COLLIER; HOEFFLER, 1998; BERDAL; MALONE, 2000; BALLENTINE; SHERMAN, 2003; PUGH; COOPER, 2004).

Perante esse quadro de conflitos persistentes e intratáveis, em cujas raízes estão graves desequilíbrios estruturais (violência estrutural) e questões étnicas e religiosas que moldam as identidades dos grupos em conflito (violência cultural), é importante notar os desenvolvimentos doutrinários e institucionais ocorridos no âmbito da ONU, que trazem os estudos da paz para o centro do seu modelo de intervenções e influenciam significativamente a expansão da sua doutrina de operações de paz nos anos 1990 e 2000. Na "Agenda para a Paz" (ONU, 1992), onde o então Secretário-Geral Boutros-Ghali defende o envolvimento mais ativo da comunidade internacional na prevenção e na gestão dos conflitos violentos, as abordagens à paz definidas no trabalho de Galtung em meados da década de 1970, já comentadas na seção anterior, são trazidas para o centro das práticas de intervenção da ONU. Nesse documento, Boutros-Ghali propõe quatro tipos de operações que, se aplicados em conjunto, podem prevenir o conflito antes que ele se converta em violência (preventive diplomacy), parar o conflito após a violência ter sido deflagrada (peacemaking), manter a paz após um acordo ter sido alcançado (peacekeeping) e consolidar a paz na fase pós-conflito, através das mudanças estruturais necessárias ao bem-estar das pessoas e à redução das desigualdades sociais, contribuindo assim para evitar novas ondas de violência no futuro (peacebuilding).

Nesse contexto, há um crescimento significativo na quantidade de operações de paz a partir dos anos 1990, acompanhado de mudanças fundamentais na sua composição e nas suas funções. No que se refere à composição, as operações 
de paz passam a incorporar atores tão diversos quanto militares, policiais, diplomatas, agentes humanitários, organizações não-governamentais, agências de desenvolvimento e empresas privadas de segurança. Para além dessa diversidade de composição, as funções desempenhadas pelas operações de paz também se multiplicam, passando a abranger um amplo leque de atividades de natureza militar, política e humanitária. Na base dessa expansão do modelo de intervenções da ONU encontra-se subjacente o compromisso de mobilizar esforços não só para exercer uma influência coerciva sobre os beligerantes no sentido de se produzir uma paz negativa, mas também para criar as condições para uma paz positiva através de medidas econômicas, culturais, políticas, técnicas, humanitárias e legais capazes de promover as transformações sociais necessárias à consolidação da paz (RAMSBOTHAM; WOODHOUSE; MIALL, 2008). Se essa cooptação dos estudos da paz pela ONU indica, por um lado, a realização política do ideal normativo da disciplina, colocando a pesquisa da paz dentro do que se pode chamar de "policy-oriented mainstream" (PUREZA; CRAVO, 2005, p. 10), não se pode deixar de notar, por outro lado, que os desenvolvimentos subsequentes, inclusive através da crescente adoção de um aparato militar mais robusto e da autorização de operações sob o capítulo VII da Carta da ONU, com mandato para o uso da força, caminham para um modelo hegemônico de pacificação de periferias instáveis que traem, de forma contundente, os propósitos transformativos e emancipatórios originais dos estudos da paz, especialmente de sua agenda dedicada à paz positiva.

Em função desse quadro de conflitos persistentes e intratáveis e dos rumos tomados pelo modelo de intervenções da ONU a partir dos anos 1990, as questões relacionadas à transformação de conflitos e à consolidação da paz emergem como o núcleo de preocupação central da agenda dos estudos da paz nas últimas duas décadas. Na base da ideia de transformação de conflitos está a percepção de que os conflitos persistentes não podem ser "resolvidos" ou "solucionados", mas sim "transformados". Embora essa noção já esteja subjacente na obra de Galtung com a ideia de que as violências estrutural e cultural precisam ser transformadas para se alcançar uma paz positiva, é apenas em meados da década de 1990, em seu livro Peace by Peacefull Means, que a sua teoria da paz se conecta explicitamente à noção de transformação de conflitos. Nessa obra, o autor propõe que o conceito de paz seja definido não só em função da violência, mas também em função do conflito; a partir dessa proposta, Galtung chega à seguinte definição: " $a$ paz é a transformação do conflito de forma criativa e não violenta"9 (1996, p. 9, itálico

9 Tradução livre do autor: "peace is nonviolent and creative conflict transformation". 
no original). Com isto, o autor pretende chamar a atenção para a necessidade de transformar as atitudes, comportamentos e contradições que estão na base dos conflitos sociais, a fim de que uma paz abrangente e sustentável seja alcançada. Na base da transformação de conflitos está, portanto, a ideia de que os conflitos são inerentes às relações sociais e, como tal, não podem ser negados e nem sufocados, mas sim transformados de forma criativa e não violenta através de um processo complexo e de longo prazo (1996).

Ainda que se deva destacar a pluralidade das abordagens e pontos de vistas dos autores que se dedicam, desde os anos 1990, à reflexão sobre a transformação de conflitos, uma forma simplificada de síntese desse debate é situá-lo em termos de uma crítica à noção de resolução de conflitos. Conforme destaca Raimo Väyrynen (1999), as receitas de pronto uso e a busca de resultados de curto impacto que geralmente regem as teorias tradicionais de resolução de conflitos negligenciam a complexidade estrutural das situações de conflito e as profundas incompatibilidades de interesses e valores entre os atores envolvidos. Por essa razão, as abordagens que tentam controlar ou eliminar a violência direta resultam em esforços inúteis, a menos que a necessidade de transformação do contexto social e cultural do conflito seja também considerada (VÄYRYNEN, 1991). Dessa perspectiva, a questão chave na transformação de conflitos é identificar as raízes da violência e avaliar a maleabilidade dessas raízes, a fim de que os esforços de transformação possam ser bem-sucedidos (VÄYRYNEN, 1999).

John P. Lederach concorda com essa perspectiva transformativa ao defender a necessidade de se ir ao "epicentro" do conflito (isto é, às suas raízes principais e profundas) para que uma paz sustentável seja alcançada (2003). Embora esse autor não desconsidere a importância de medidas de resolução dirigidas às expressões visíveis da violência, é o foco no epicentro que permite identificar e propor medidas transformativas, voltadas para a reestruturação das relações de violência a longo prazo (2003). Segundo Lederach, essa reestruturação pode ser concretizada não só através da educação, ativismo não violento e mediação (1995), mas também através de uma estratégia de intervenção multidimensional, multinível e multitemporal que valorize a participação de um amplo leque de atores, externos e locais, com especial destaque para os atores não oficiais, membros da sociedade civil e vozes normalmente marginalizadas no contexto do conflito (1997).

É importante notar que essa perspectiva transformativa tem sido integrada a outros debates nascentes na disciplina. Uma dessas agendas tem procurado ir além da reflexão sobre as novas guerras, a fim de destacar o que alguns acadêmicos 
têm chamado de "novíssimas guerras" (MOURA, 2010), "novo urbanismo militar" (GRAHAN, 2010), "guerras urbanas" (BEALL, 2006), "guerras de favelas" (RODGERS, 2009), "cidades frágeis" e "cidades falhadas" (BEALL; GOODFELLOW; RODGERS, 2013; LIOTTA; MISKEL, 2012; MUGGAH, 2014). Essa bibliografia compõe um amplo mosaico de abordagens que, resguardadas as suas particularidades (algumas mais críticas e emancipatórias, outras mais conservadoras e estratégicas), giram em torno de um eixo comum: a intensificação da violência armada e o crescente processo de militarização das grandes metrópoles. Dentro de um quadro de relativo declínio das guerras entre Estados, o que parece crucial nessa bibliografia, do ponto de vista da transformação de conflitos, é a constatação de uma escala cada vez mais microscópica de conflitos violentos, concentrados em microterritórios dos grandes centros urbanos, inclusive em contextos nacionais de paz aparente e formal (MOURA, 2010).

Nessa agenda, o trabalho de Tatiana Moura (2010) assume um viés particularmente crítico e reflexivo ao examinar a escala microssocial de conflitos de uma perspectiva feminista. Com base na análise da violência armada nas grandes cidades, particularmente no Rio de Janeiro, a autora observa formas diretas e indiretas de violência (estrutural e cultural) que perpetuam sistemas de poder em microescala e submetem as populações locais, principalmente as mulheres e crianças, a uma espiral de inseguranças. Embora essas dinâmicas de violência produzam níveis elevados de tensão, Moura destaca que elas são negligenciadas dentro das teorias, narrativas e práticas dominantes de construção da paz. O que parece crucial nesse debate, do ponto de vista da transformação de conflitos, é a necessidade, já enfatizada por Lederach, de uma abordagem multinível que dê visibilidade às vozes geralmente marginalizadas nos contextos microssociais dos conflitos. Ao chamar a atenção para a "hiperconcentração" de violência urbana, que se dilui e se oculta num contexto de paz institucional e formal, Moura lança como desafio a necessidade de se desvendar a construção de identidades (feminilidades e masculinidades) que legitimam e perpetuam essas "novíssimas" dinâmicas da violência armada. Só assim será possível identificar formas alternativas e não violentas de prevenção e transformação que produzam "novíssimas pazes" nesses contextos "invisíveis" e "silenciados" de violência em microescala (MOURA, 2010).

Outro debate que começa a ser articulado com a reflexão sobre transformação de conflitos resulta da recente revitalização do pensamento sobre a ação nãoviolenta. Sob o impacto das revoluções pacíficas da chamada "Primavera 
Árabe", parte da atual agenda dos estudos da paz tem retornado aos métodos de protesto, não-cooperação e intervenção pacífica. Essa temática, que já havia inspirado referências clássicas dos estudos da paz (GALTUNG, 1959; SHARP, 1973; BOULDING, 1999), tem sido trazida, principalmente por Véronique Dudouet (2008; 2015), para um quadro de reflexão sobre a transformação de conflitos em situações onde se observam relações de poder assimétricas, especialmente nos estágios iniciais de conflitos latentes enraizados em violência estrutural. Segundo essa autora, o potencial de "empoderamento" popular, de pressão sobre o oponente e de obtenção da simpatia de terceiras-partes torna a ação não violenta um instrumento útil nas mãos de comunidades marginalizadas e desprivilegiadas na busca de uma posição mais fortalecida, a partir da qual o caminho para a negociação de concessões pode se tornar propício (2008).

Considerando a capacidade da ação não violenta para transformar as relações de poder e transformar as identidades através da persuasão, Dudouet sugere uma combinação de princípios e de preocupações pragmáticas que pode fazer da ação não-violenta uma ferramenta importante de ação política capaz de atuar através de um duplo processo de diálogo e resistência: diálogo com o oponente mais poderoso (com o objetivo de persuadi-lo sobre a justiça e a legitimidade das causas defendidas pelas partes mais fracas) e resistência às estruturas injustas de poder (com o objetivo de pressionar por mudanças sociais e políticas). Ao estudar o conflito entre Israel e Palestina, Dudouet (2008) destaca, porém, que as condições para a operação desse processo dialético da não violência tendem a ser dificultadas nos estágios mais avançados do conflito ou em situações que mostram um alto grau de polarização entre grupos oponentes quanto a aspetos não negociáveis. Nesses casos mais extremos, a autora considera que a ação não violenta, isoladamente, pode não ser efetiva na prevenção de mal-entendidos e na superação dos ressentimentos entre as partes, o que sugere a necessidade de integrar a ação não-violenta dentro de uma estratégia transformativa de longo prazo que inclua múltiplas formas de intervenção, tais como a negociação, a mediação, a intervenção de terceiras-parte e outras medidas de peacemaking e peacebuilding.

Ao olhar para esse foco dos estudos da paz na transformação de conflitos e na consolidação da paz, alguns autores têm alertado, porém, para o risco de que a ideia de transformação das raízes do conflito e busca de mudanças sociais acabe resultando em projetos de engenharia social (VÄYRYNEN, 1999). Richmond (2007a) concorda com esse alerta ao criticar o grande projeto de engenharia social que se encontra subjacente à chamada "paz liberal". Segundo o autor, essa 
noção de paz, consolidada no contexto do liberalismo triunfante do pós-Guerra Fria, tem submetido as formas de intervenção e os modelos de transformação de conflitos a uma espécie de consenso sobre peacebuilding que leva à exportação do modelo institucional do Estado ocidental liberal para as zonas de conflito (2007a). Dentro desse consenso, até mesmo as perspectivas emancipatórias comprometidas com a transformação social acabam cooptadas por projetos de engenharia social, guiadas pela ideia de que transformar as raízes estruturais e culturais da violência é sinônimo de criar instituições liberais - democracia, estado de direito, direitos humanos, desenvolvimento e livre mercado (2007a). Dentro desse processo, geralmente imposto de "cima para baixo" e conduzido por agentes externos, as pessoas e as dinâmicas locais são apagadas e a almejada transformação das raízes estruturais e culturais do conflito acaba por criar uma "paz virtual" não compartilhada pelas comunidades locais, que atende mais aos objetivos de segurança das Organizações e Estados interventores do que às necessidades concretas de segurança e desenvolvimento em microescala das populações mais vitimadas pela violência (2007a).

Não se pode deixar de notar que esse projeto intervencionista se tem tornado ainda mais intrusivo e violento a partir dos ataques terroristas de setembro de 2001, quando o uso da força militar pelas potências ocidentais em típicas operações de guerra passou a ser mesclado com um projeto liberal de construção de Estado nos chamados "Estados párias" como receita de combate ao terrorismo. Estrategicamente inseridas na chamada "guerra contra o terror" (Afeganistão e Iraque) ou normativamente justificadas com base no princípio da "responsabilidade de proteger" (Líbia), essas intervenções não poupam esforços no uso da força, instituindo uma forma militarizada de ação que defende a emancipação das populações civis, a fim de evitar que elas se tornem vítimas de ditadores e grupos perigosos, ao mesmo tempo que admite a morte dessas mesmas populações como um efeito colateral da intervenção (DILLON; REID, 2009). O que se nota com base nesses desenvolvimentos é que a paz, ao ser incorporada como conceito-chave nas doutrinas e práticas de intervenção internacional no pós-Guerra Fria, convertese, segundo os críticos da paz liberal, num novo mecanismo de opressão social, numa nova forma de dominação e controle das sociedades alvos de intervenção (PUREZA; CRAVO, 2005).

Em função desses desenvolvimentos, um dos impactos mais radicais nos desdobramentos contemporâneos dos estudos da paz talvez sejam ilustrados pelo deslocamento do eixo de reflexão do conceito de "paz" para o conceito 
de "segurança" ocorrido na agenda de diversos pesquisadores anteriormente vinculados aos estudos da paz. Para esse grupo de pesquisadores, muitos deles oriundos do Instituto de Pesquisa da Paz de Copenhague (Copenhagen Peace Research Institute - COPRI), extinto em 2003 e incorporado ao Instituto Dinamarquês para Estudos Internacionais, o conceito de segurança, em vez do conceito de paz, passou a ser a categoria-chave através da qual a crítica ao mainstream dos estudos internacionais pode ser conduzida no pós-Guerra Fria (BUZAN; HANSEN 2009, p. 135; WAEVER 2004). A esse respeito, as palavras de Ole Waever são contundentes: se os estudos da paz representaram o grande desafio crítico aos estudos estratégicos durante a Guerra Fria, recusando-se a aceitar a política oficial do Ocidente quanto às questões de segurança, hoje as coisas inverteram-se e a paz tornou-se um dos conceitos dominantes na formulação de políticas no mundo ocidental, servindo inclusive para justificar intervenções violentas; desse modo, se por um lado "a segurança é potencialmente o nome de uma agenda radical, subversiva”10 (e aqui Waever está se referindo, obviamente, à emergência dos estudos críticos de segurança, que desde o fim da Guerra Fria se tem nutrido das perspectivas radicais pós-positivistas), por outro lado a pesquisa da paz pode ser considerada datada porque a paz se tornou tão doutrinária que o conceito deixou de ser "intelectualmente interessante" (2004, p. 63).

Se as palavras do parágrafo acima refletem com propriedade a expansão do conceito de segurança como forma de desafiar as perspectivas realistas e estratégicas no pós-Guerra Fria, elas soam injustas com os esforços de diversos estudiosos da paz no sentido de incorporar em suas agendas uma orientação igualmente radical e emancipatória. Adotando uma perspectiva reflexiva e defendendo uma pluralidade metodológica aberta às influências da teoria crítica, do pós-estruturalismo, do pós-colonialismo, do feminismo (CHANDLER, 2010; DILLON; REID, 2009; DUFFIELD, 2001, 2007, 2010; JABRI, 2013; MAC GINTY 2008; MOURA, 2010; PORTER, 2007; PUGH 2005; PUREZA, 2011; RICHMOND 2007a, 2011a, 2011b; RICHMOND; MITCHELL 2012; TURNER, 2012), ou defendendo uma perspectiva estética voltada para o papel da emoção e das expressões artísticas na construção da paz (BLEIKER, 2009; RICHMOND, 2007b; HUTCHISON; BLEIKER, 2008), esses trabalhos têm contribuído para colocar os estudos da paz em dia com os desenvolvimentos epistemológicos e metodológicos mais recentes e para reforçar a radicalidade do programa de paz positiva originalmente vislumbrado na obra de Galtung.

10 Tradução livre do autor: "security is potentially the name of a radical, subversive agenda”. 


\section{Conclusões}

Os estudos da paz desenvolveram-se em torno de duas grandes orientações. De um lado, a disciplina assumiu um perfil conservador, voltado para as explanações mais convencionais e minimalistas da paz, focado nas manifestações diretas da violência e na solução dos problemas específicos gerados pela guerra propriamente dita. Os resultados alcançados por essa linha mais conservadora, predominantemente neopositivista em sua abordagem metodológica, não podem ser negligenciados: os estudos da paz estão hoje institucionalizados em centenas de universidades e centros de investigação em todo o mundo e o manancial acumulado de pesquisas rigorosas, detalhadas, documentadas e empiricamente testadas sobre as causas dos conflitos e das guerras e sobre a eficácia das técnicas e métodos de resolução de conflitos podem ser escrutinadas em mais de sessenta volumes do Jornal of Conflict Resolution e mais de cinquenta volumes do Journal of Peace Research - revistas hoje situadas entre as publicações científicas com maior fator de impacto no campo das Relações Internacionais.

Ainda que seja importante reconhecer esse o mérito, é igualmente relevante notar que, para confrontar as questões estruturais e culturais que estão nas raízes mais profundas do conflito e da paz, nem sempre visíveis e mensuráveis pelos protocolos objetivos neopositivistas, é preciso estimular o desenvolvimento da segunda orientação da disciplina, mais radical, maximalista, crítica e reflexiva, voltada para uma visão transformadora e emancipatória do mundo. Se a consolidação e institucionalização dos estudos da paz como disciplina rigorosa passou pela necessidade de sua afirmação como ciência empirista fundamentalmente voltada para as questões técnicas colocadas no campo da resolução de conflitos e reconstrução pós-bélica, a longa trajetória intelectual de Galtung e os desafios transformativos colocados pela conflitualidade contemporânea reforçam a necessidade de um constante trabalho de conceptualização da paz e de busca de novas perspectivas que sejam capazes de penetrar nas camadas mais profundas, nem sempre visíveis, de um mundo marcado por conflitos cada vez mais complexos, multidimensionais, multiníveis e, portanto, diferentes do conflito macrossocial entre as superpotências que marcou o nascimento dos estudos da paz. Nesse sentido, a abertura da disciplina para a pluralidade epistemológica e metodológica, incorporando as viradas construtivista, crítica, pós-estruturalista, pós-colonialista, feminista e estética que têm impactado o estudo da política internacional, bem como para as novas formas através das quais a violência e os conflitos se manifestam no 
mundo contemporâneo, deve ser vista como uma via essencial para que a paz se mantenha como um conceito intelectualmente desafiador, fiel à radicalidade que os estudos da paz trazem no seu DNA desde o seu nascimento.

\section{Referências}

AZAR, Edward. The Management of Protracted Social Conflict: Theory \& Cases. Aldershot: Dartmouth, 1990.

AZAR, Edward. Protracted Social Conflicts and Second Track Diplomacy. In DAVIES, J.; KAUFMAN, E. (Eds.) Second Track/ Citizens' Diplomacy: Concepts and Techniques for Conflict Transformation. Oxford: Rowman \& Littlefield, 2003, Capítulo 1, p. 15-30.

BALLENTINE, Karen; SHERMAN, Jake. The political Economy of Armed Conflict: beyond greed and grievance. London: Lynne Rienner, 2003.

BEALL, Jo. Cities, Terrorism and Development. Journal of International Development, v.18, n. 1, 2006, p. 105-120.

BEALL, Jo; GOODFELLOW, Tom; RODGERS, Dennis. Cities and conflict in fragile states in the developing world. Urban Studies, v.50, n.15, 2013, p. 3009-3115.

BERDAL, Mats; MALONE, David M. (Eds.). Greed and Grievance: economic agendas in civil wars. Boulder: Lynne Rienner, 2000.

BLEIKER, Roland. Aesthetics and World Politics. New York: Palgrave Macmillan, 2009.

BOULDING, Keneth. Nonviolence and Power in the Twentieth Century. In ZUNES, S.; KURTZ, L. B.; ASHER, S. B. (Eds.) Nonviolent Social Movements: A Geographical Perspective. Oxford: Blackwell Publishing, 1999, Capítulo 1, p. 9-17.

BUZAN, Barry; HANSEN, Lene. The Evolution of International Security Studies. Cambridge: Cambridge University Press, 2009.

CHANDLER, David. International Statebuilding: The Rise of Post-Liberal Governance. London: Routledge, 2010.

COLLIER, Paul; HOEFFLER, Anke. On Economic Causes of Civil War. Oxford Economic Papers, v. 50, 1998, p. 563-573.

DENCIK, Lars. Peace Research: Pacification or Revolution? Notes on an Intra-peace Research Conflict. In International Peace Research Association Proceedings, 3rd General conference, v. 1, 1970, p. 79.

DILLON, Michael; REID, Julian. The Liberal way of War: Killing to make Life Live. Londres: Routledge, 2009.

DUDOUET, Véronique. Nonviolent Resistance and Conflict Transformation in Power Asymmetries. Berlin: Berghof Research Center for Constructive Conflict Management, 2008. 
DUDOUET, Véronique. Civil Resistance and Conflict Transformation: Transitions from Armed to Nonviolent Struggle. Abingdon: Routledge, 2015.

DUFFIELD, Mark. Global Governance and the New Wars: The Merging of Development and Security. London: Zed Books, 2001.

DUFFIELD, Mark. Development, Security and Unending War: Governing the World of Peoples. Cambridge: Polity Press, 2007.

DUFFIELD, Mark. The Liberal Way of Development and the Development-Security Impasse: Exploring the Global Life-Chance Divide. Security Dialogue, v. 41, n. 1, 2010, p. 53-76.

DUNN, David J. The First Years of Peace Research: A Survey and Interpretation. Aldershot: Ashgate, 2005.

GALTUNG, Johan. Pacifism from a Sociological Point of View. Journal of Conflict Resolution, v. 3, n. 1, 1959, p. 67-84.

GALTUNG, Johan. Violence, Peace and Peace Research. Journal of Peace Research, v. 6, n. 3, 1969, p. 167-191.

GALTUNG, Johan. A Structural Theory of Imperialism. Journal of Peace Research, v. 8, n. 2, 1971, p. 81-117.

GALTUNG, Johan. Three Approaches to Peace: Peacekeeping, Peacemaking and Peacebuilding. In GALTUNG, Johan (Ed.) Essays in peace research, vol. 2. Copenhagen: Ejlers, 1976, Capítulo II, p. 282-304.

GALTUNG, Johan. Twenty-Five Years of Peace Research: Ten Challenges and Some Responses. Journal of Peace Research, v. 22, n. 2, 1985, p. 141-158.

GALTUNG, Johan. Cultural Violence. Journal of Peace Research, v. 27, n. 3, 1990, p. 291-305. GALTUNG, Johan. Peace by Peacefull Means. London: SAGE, 1996.

GALTUNG, Johan. Peace Studies and Conflict Resolution: The Need for Transdisciplinarity. Transcultural Psychiatry, v. 47, n. 1, 2010, p. 20-32.

GRAHAM, Stephen. Cities under Siege: The New Military Urbanism. London: Verso, 2010. HUTCHISON, Emma; BLEIKER, Roland. Emotional Reconciliation Reconstituting Identity and Community after Trauma. European Journal of Social Theory, v.11, n.3, 2008, p.385-403.

JABRI, Vivienne. Peacebuilding, the local and the international: a colonial or a postcolonial rationality? Peacebuilding, v.1, n. 1, 2013, p. 3-16.

JCR. An Editorial. Journal of Conflict Resolution, v. 1, n. 1, 1957, p. 1-2.

JPR. An Editorial. Journal of Peace Research, v. 1, n. 1, 1964, p. 1-4.

KALDOR, Mary. New and Old Wars: organized violence in a global era. Cambridge: Polity Press, 1999.

KEEN, David. The economic functions of violence in civil wars. Oxford: Oxford University Press, 1998. 
LEDERACH, John P. Preparing for Peace. Conflict Transformation Across Cultures. Syracuse: Syracuse University Press, 1995.

LEDERACH, John P. Building Peace: Sustainable Reconciliation in Divided Societies. Washington, D.C.: United States Institute of Peace Press, 1997.

LEDERACH, John P. The Little Book of conflict transformation. Intercourse: Good Books, 2003.

LIOTTA, P.; MISKEL, J. The Real Population Bomb: Megacities, Global Security \& the Map of the Future. Dulles: Potomac Books, 2012.

MAC GINTY, Roger. Indigenous Peace-Making versus the Liberal Peace. Cooperation and Conflict, v. 43, n. 2, 2008, p. 139-163.

MOURA, Tatiana. Novíssimas Guerras: Espaços, Identidades e Espirais da Violência Armada. Coimbra: Almedina, 2010.

MUGAH, Robert. Deconstructing the fragile city: exploring insecurity, violence and resilience. Environment \& Urbanization, v.26, n.2, 2014, p.345-358.

ONU. A/3302 (1956) Report of the Secretary-General on the plan for an emergency international United Nations force. New York: United Nations, 1956.

ONU. A/47/277 (1992) An Agenda for Peace. New York: United Nations, 1992.

PORTER, Elisabeth. Peacebuilding: Women in international perspective. London: Routledge, 2007.

PUGH, Michael; COOPER, Neil. War economies in a regional context: challenges of transformation. London: Lynne Rienner, 2004.

PUGH, Michael. The Political Economy of Peacebuilding: A Critical Theory Perspective. International Journal of Peace Studies, v. 10, n. 2, 2005, p. 23-42.

PUREZA, José Manuel. O Desafio Crítico dos Estudos para a Paz. Relações Internacionais, v. 32, 2011, p. 5-22.

PUREZA, José Manuel; CRAVO, Teresa. Margem crítica e legitimação nos estudos para a paz. Revista Crítica de Ciências Sociais, v. 71, 2005, p. 5-19.

RASMUSSEN, Mikkel V. The West, Civil Society and the Construction of Peace. Basingstoke: Palgrave, 2003.

RAMSBOTHAM, Oliver; WOODHOUSE, Tom; MIALL, Hugh. Contemporary Conflict Resolution. Cambridge: Polity Press, 2008.

RENO, William. Warlord Politics and African States. Boulder: Lynne Rienner, 1999.

RICHMOND, Oliver P. The Transformation of Peace. Basingstoke: Palgrave, 2007a.

RICHMOND, Oliver P. Dadaism and the Peace Differend. Alternatives, v. 32, n. 4, 2007b, p. $445-472$.

RICHMOND, Oliver P. A Post-liberal Peace. Abingdon: Routledge, 2011a.

RICHMOND, Oliver P. Critical agency, resistance and a post-colonial civil society. Cooperation and Conflict, v. 46, n. 4, 2011b, p. 419-440. 
RICHMOND, Oliver P.; MITCHELL, Audra (org.). Hybrid Forms of Peace: From Everyday Agency to Post-Liberalism. Basingstoke: Palgrave, 2012.

RODGERS, Dennis. Slum wars of the 21st century: gangs, mano dura and the new urban geography of conflict in Central America. Development and Change, v.40, n.5, 2009, p. 949-976.

SHARP, Gene. The Politics of Nonviolent Action (Vol. I - Power and Struggle; Vol. II The Methods of Nonviolent Action; Vol. III - The Dynamics of Nonviolent Action). Boston: Porter Sargent Publishers, 1973.

SCHMID, Herman. Peace Research and Politics. Journal of Peace Research, v. 5, n. 3, 1968, p. 217-232.

STOHL, Michael; CHAMBERLAIN, Mary. Alternative futures for peace research. Journal of Conflict Resolution, v. 16, n. 4, 1972, p. 523-530.

TURNER, Mandy. Completing the Circle: Peacebuilding as Colonial Practice in the Occupied Palestinian Territory. International Peacekeeping, v. 19, n. 4, 2012, p. 492-507.

VÄYRYNEN, Raimo (ed.). New Directions on Conflict Theory: Conflict Resolution and Conflict Transformation. London: Sage, 1991.

VÄYRYNEN, Raimo. From Conflict Resolution to Conflict Transformation: A Critical Review. In JEONG, Ho-Won (Ed.) The New Agenda for Peace Research. Aldershot: Ashgate, 1999, Capítulo 7.

WAEVER, Ole. Peace and Security: Two concepts and their relationship. In GUZZINNI, Stefano e JUNG, Dietrich (Eds.) Contemporary Security Analysis and Copenhagen Peace Research. London: Routledge, 2004, Capítulo 5, p. 53-66.

WIBERG, Hakan. Investigação para a Paz: Passado, Presente e Futuro. Revista Crítica de Ciências Sociais, n. 71, 2005, p. 21-42. 